\title{
Impact of Mixed Reality Presentation on STEM Engagement and Comprehension: A Pilot Study on Adult Scientists
}

\author{
Peter Geller, ${ }^{1}$ Jaymie Stein, ${ }^{2}$ Daniel Du, ${ }^{3}$ Jason R. Webb,${ }^{4}$ \\ Zack Lieberman, ${ }^{4}$ David Shreiber, ${ }^{3}$ and Biju Parekkadan id ${ }^{1}$ Department of Surgery, Massachusetts General \\ Hospital, Harvard Medical School, Boston, USA; ${ }^{2}$ Department of Graduate Education, Fordham University, New York, \\ NY 02212, USA; ${ }^{3}$ Department of Biomedical Engineering, Rutgers University, Piscataway, NJ 08854, USA; And ${ }^{4}$ Zyndo, \\ LLC, BROOKLYN, NY, USA
}

(Received 1 October 2020; accepted 22 February 2021; published online 9 April 2021)

\begin{abstract}
Current educational presentation software used in STEM education fail to maximize student engagement and comprehension. Mixed reality presentation is one specific type of digital presentation software that has shown to significantly improve student engagement and comprehension. In this paper, we describe a pilot study on adult scientists which evaluates the usage of an integrated mixed reality presentation software in the Zyndo platform as an enhanced alternative to Adobe PDFs. A group of adult scientists $(N=20)$, with higher education of at least a bachelor's degree, from an academic research center at Harvard Medical School were randomized and asked to read two articles (one on Immunology and the other on Bioengineering) presented through either the mixed reality presentation or PDFs. Our results indicate that participants improved in nearly all metrics for engagement (ranging from +4 to $51 \%$ improvement depending on engagement metric and subject matter) when viewing the mixed reality presentation over the traditional PDFs for both articles. Specifically, the participants demonstrated improved comprehension of the scientific content and time spent viewing the presentation in a content-dependent manner. Therefore, 3D mixed reality environments can potentially be applied to enhance student learning in STEM fields, particularly Biomedical Engineering in both on-line and in person classroom settings.
\end{abstract}

Keywords-Mixed reality, Virtual reality, Augmented reality, Education, Learning, Engagement, Enjoyment, Comprehension, Presentation software, Science technology engineering math.

Address correspondence to Biju Parekkadan, Department of Surgery, Massachusetts General Hospital, Harvard Medical School, Boston, USA. Electronic mail: biju.parekkadan@rutgers.edu

Peter Geller and Jaymie Stein contributed equally.

\section{INTRODUCTION}

Science textbooks have traditionally included more information about inventions or products as opposed to science processes, ${ }^{14,15}$ and often times, the way the information is presented makes it challenging for students to understand, especially if they have low reading skills. ${ }^{8}$ Over the years, digital technology has found its avenue in science, technology, engineering, and mathematics (STEM) education. More schools have started incorporating digital presentations in classroom settings. While current software such as Adobe PDF complement traditional STEM education, they are comprised of static 2D elements and often mimic nondigital teaching techniques. Basic text and figure layout structure in academic lessons provide students less motivation to dive deeper into scientific content thereby affecting overall academic performance. ${ }^{18}$ This aspect turns lectures into monologues and affects student engagement levels and comprehension abilities. ${ }^{32}$

US Department of Education identifies engagement and comprehension as key factors contributing to student success (2026 STEM Vision). ${ }^{30}$ Academic engagement is multidimensional and examined within three components including behavioral (on-task behavior, persistence, class participation), cognitive (analytical aspects to solve problems), and affective (attitude and interest level). ${ }^{3}$ Drawing on knowledge about achievement motivation, engaging students in school is greatly influenced by pedagogical approaches $\left.{ }^{7,28}\right)$. For example, evidence suggests that ICT nurtures learning through a student-centered approach that encourages active learning. ${ }^{22}$ In such a 
climate, students report higher levels of engagement compared to students in a teacher-centered approach because they feel more competent in their individual abilities while also feeling a sense of belonging. ${ }^{9}$ When students have the opportunity to construct their own meanings through different ways of learning, their engagement levels rise $^{10}$ ). While there is a dearth of research about the relationship between digital technology and engagement, teachers have reported higher levels of engagement for their students when using technology as learning tools. ${ }^{26,28}$

Mixed reality (MR) technologies, often combining aspects of virtual reality (VR) or augmented reality (AR), are becoming increasingly popular in classrooms because they behaviorally, cognitively, and affectively engage students. MR blends real and virtual worlds using computer-generated objects. The two worlds are "mixed" together to create a realistic environment, so that users can seamlessly navigate content and "physically" interact with real and virtual objects with the aid of a digital display device (e.g., a smart phone). For instance, middle schoolers who learned gravity and planetary motion using a virtual reality environment revealed significant learning gains, higher levels of engagement, and more positive attitudes toward sciences while using an immerse, whole-body interactive simulation rather than a desktop version of the same simulation. ${ }^{20}$ In another experiment, eighth graders exhibited significant improvement in their learning attitudes and outcomes for magnetic field instruction using AR technology instead of traditional lab equipment. ${ }^{4}$ Similarly, AR technologies have shown to improve student learning and retention, ${ }^{16}$ especially in STEM areas such medical surgery education, ${ }^{17}$ molecular modeling, ${ }^{27}$ and astronomy. ${ }^{21}$ AR technologies also simplify multidimensional concept maps and enable students to stay motivated and understand content better. ${ }^{6}$ The increase of online instruction requires that digital platforms be developed and validated by looking at engagement levels and academic achievement in comprehension.

In this study, we investigate the effectiveness of MR technology created by Zyndo LLC for Biomedical Engineering and Immunology disciplines. The Zyndo platform creates educational stories, which are referred to as Z-books, in an interactive and immersive MR environment. To improve upon the static $2 \mathrm{D}$ elements of PDFs, our MR presentation combines 2D text and images to form a $3 \mathrm{D}$ space containing interactive models and objects students can interact with using a smart device. An important innovation of Z-books is that users can freely navigate content in a non-linear way with multiple story path options and advanced triggering of special objects, thereby supporting novice and advanced users alike. Offering a wide selection of language, audio, tactile, and visual capabilities, this MR presentation may provide a flexible digital technology to benefit all types of learners. Comprehension strategies, such as reading and taking margin notes are applied using advanced technology as students are encouraged to explore the MR presentation in a way that challenges their critical and relational thinking in a 3D relatable way. The video-game-adventure-like setting of this MR presentation especially appeals to younger students, who are immersed in a technologydriven world. ${ }^{1}$

This pilot study was performed on higher education students to first verify the effects of MR on students who are more adept to learning, though are recognized as demographically different from undergraduate or K-12 students. A controlled, randomized group of STEM professionals $(N=20)$ from an academic, biomedical engineering research center at Harvard Medical School were given two articles to read from the journal Science $e^{11,31}$ as summarized in Z-book or PDF format. While the STEM professionals viewed the article presentations, we recorded their total time spent doing so. Once the STEM professionals finished reading one article in Z-book or PDF format, they were given the other article presented in the other format. After the STEM professionals finished reading either article, they were given a multiple-choice sheet containing comprehension questions that corresponded to the article, followed by survey engagement questions. These questions were developed by a committee of by the senior authors with domain/educational expertise. When the STEM professionals finished reading and experiencing the articles and PDF presentations, a focus group took place and researchers took notes using an observation protocol.

\section{METHODS}

\section{Before Experimental Portion}

Prior to the experiment, two scientific articles, one on Immunology (Anticancer immunotherapy by CTLA-4 blockade relies on the gut microbiota. Science, Nov 27; 2015, https://doi.org/10.1126/science.aa d1329) and the other on Bioengineering (First-in-Human Testing of a Wirelessly Controlled Drug Delivery Microchip. Science Translational Medicine, Feb 16, 2012 DOI: https://doi.org/10.1126/scitranslmed.30032 76) had been turned into interactive Z-book presentations. Both presentations were recreated, as faithfully as possible, in PDFs. Participants were found in two ways. The first was direct advertising, in which we posted flyers in both Shriner's Hospitals for Children and Massachusetts General Hospital. An email asking 
for participants was also sent on an internal hospital listing. The second way was the "snowball method," meaning we used the participants we initially found to find more participants. All 20 participants were aged 21-40 and received an advanced scientific degree (BS, MS, PhD, MD, MD/PhD). We first met with each participant in a private session, discussing what the study involved. After this, we gave each participant a sheet asking for background information and asked them to fill it out. With all the questions answered, the experimental portion began.

\section{During Experimental Portion}

All four versions of the articles (Z1, Z2, PDF1, PDF2) were loaded onto tablet devices. Each participant was given the first tablet and was asked to read the article presentation. While the participant read, we observed and answered basic questions and comments. We also timed the participant on a stopwatch from the start of the article to the end. When the participants indicated they were finished reading, they were given a sheet containing comprehension questions for the article they read. Five multiple choice comprehension questions for each article were written and provided to test whether participants learned more depending on the presentation format. Below the comprehension questions were survey questions, which were meant to provide a quantitative measure of engagement. We used a combination of a pre-existing standard scale, called the System Usability Scale, and our own questions. ${ }^{29}$ Survey questions were meant to represent very basic criteria that are important for students to know.

When the participants finished answering, we gave them the second tablet loaded to the other article presentation in the other format. For each participant, the order of article and format was rotated. (So, Z1/ PDF2 then PDF1/Z2 then Z2/PDF1 then PDF2/Z1 then the same rotation again.) In this way, we ensured that the contents of the article and the order they were read did not impact the experiment. When the participants finished reading, they were given a sheet containing comprehension questions for the second article followed by the same survey questions that followed the first. After participants finished answering these questions, we moved on to an open-ended discussion. This lasted until the end of each participant's allotted time. We tried to get each participant to talk about their experience, likes, dislikes, etc. While the conversation was free-flowing, we had a list of Usability Questions adapted from standard usability testing surveys. We took notes on their comments, writing down verbatim quotes when possible and later typing up these quotes in combination with the background information.

\section{After Experimental Portion}

Following the completion of the experimental aspect, we marked each comprehension question correct/ incorrect, totaled correct answers, etc. We then created an Excel file that contained every participant's correct/ incorrect answers, the total correct answers for each file, file type, and the ratings each participant gave in the survey questions.

\section{RESULTS}

\section{$M R$ Presentation Provides an Immersive and Interactive Learning Environment}

Among other features, MR presentation improves upon standard 2D learning environments through an interactive 3D user interface. Traditional presentation software have users swipe or scroll through pages of static, non-interactive elements, which are suboptimal for maximizing students' learning (Fig. 1a). However, MR presentation can take these $2 \mathrm{D}$ images and position them within an immersive, infinite 3D environment (Fig. 1b). Users are then able to explore the presentation on their own through a virtual camera. Our MR presentation is built using video gaming language and incorporates multiple story paths for users to choose the information they want to hear more about. Moreover, the audiovisual interface is integrative, allowing for an accessible interactive presentation of nearly any information in a $3 \mathrm{D}$ environment with the inclusion of complex 2D or 3D elements, a robust synced audio engine, and advanced triggering of new content via nuanced user interactions (Fig. 1c). This multi-sensory engagement of touch, sight, and sound creates a deeply immersive experience for users of varying academic abilities and needs. Furthermore, built-in language translation capabilities allow our MR presentation software to reach international users. The audio engine is especially multifaceted, as it combines detailed narrations, sound effects, and pre-developed soundtracks (Fig. 1d). With its unique 2D-to-3D parallax system and zooming function, our MR presentation effectively brings stories to life by making static 2D images look 3D (Fig. 1e).

\section{$M R$ Presentation Improved Nearly all Immunology and Bioengineering Engagement Individual Question Scores}

To first explore the affect of participants, they completed an academic engagement survey immediately following their digestion of both the written content and Zyndo MR created content, which measured their affective, cognitive, and behavioral 
engagement. The 10-item instrument was developed based on pre-existing measures of engagement, 5,13 adapted for STEM graduate students. Each of the items were rated on a 5-point-scale where $1=$ strongly disagree and $5=$ strongly agree (see Appendix A). We found that generally, users preferred the MR presentation over traditional PDFs (Fig. 2). In almost all metrics related to engagement, MR presentation users reported that they were more engaged with and better enjoyed both the Immunology and Bioengineering MR presentations than did the PDF users. The only engagement question in which PDF users outscored MR presentation users was pertaining to the Bioengineering presentation's navigation, with an improvement of $-2.70 \%$. Still, this difference had the lowest magnitude of all the engagement questions for both Immunology and Bioengineering articles, showing that MR presentation has a significant positive effect on engagement for STEM learners. As they relate to affective engagement (i.e. I am likely to recommend this presentation software to a friend or colleague), MR presentation users felt more strongly that they would like to read on, create with, and recommend the software than PDF users did for the Immunology article. This finding suggests MR environments are more affectively engaging than PDFs.

\section{$M R$ Presentation Significantly Improved Overall Immunology and Bioengineering Engagement}

After all the individual engagement scores for each MR presentation or PDF group were compiled, we next explored participant affect as measured by total engagement. Total engagement scores were calculated by taking the average and then dividing by the maximum score of 5 to obtain a percentage (Fig. 3). For the Immunology article, MR presentation users had an average engagement score of $82.67 \%(\sigma=0.28)$, while PDF users had an average engagement score of $70.91 \%(\sigma=0.47)$. A $t$ test was performed on the raw
A

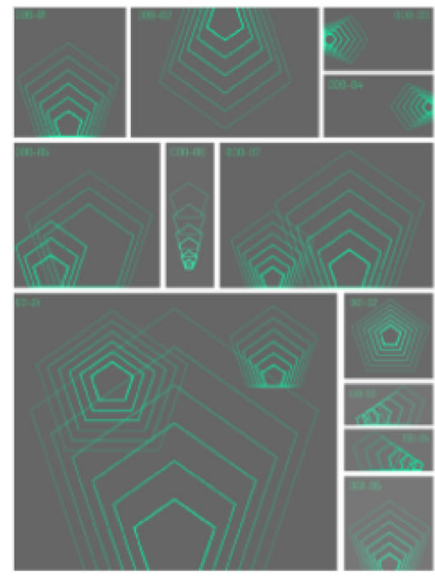

C

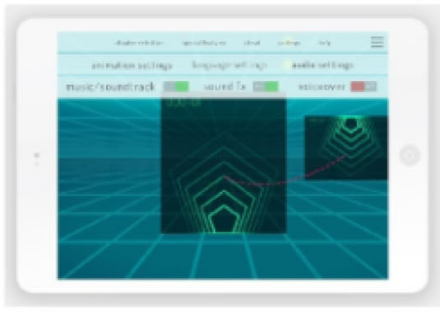

B

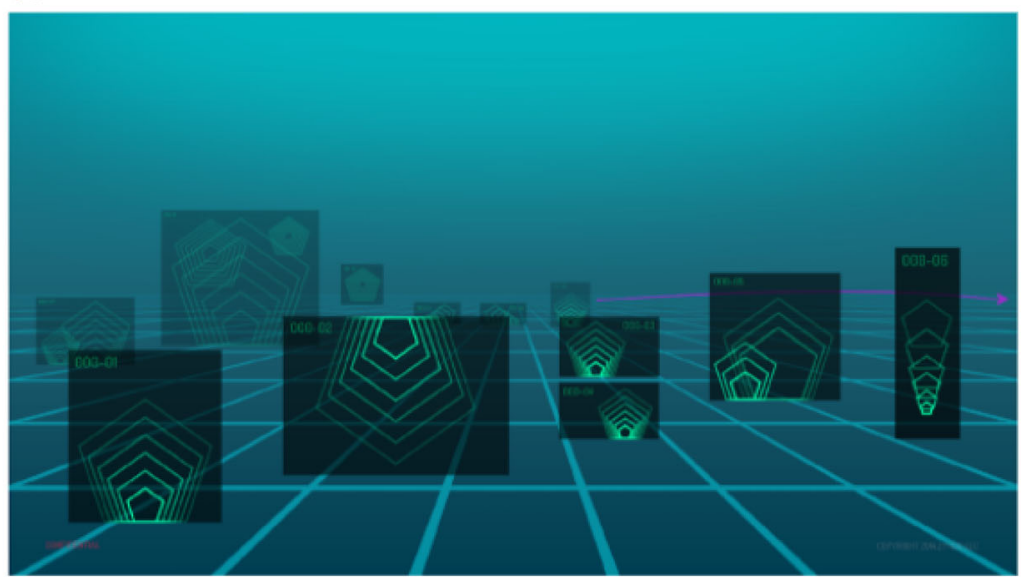

D

E

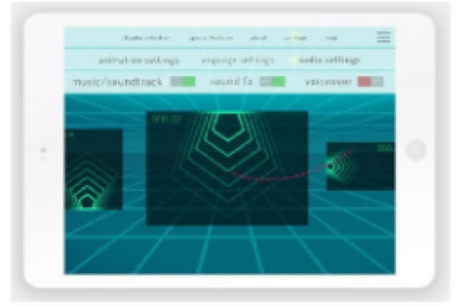

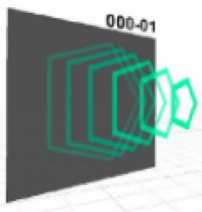

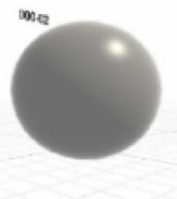

FIGURE 1. Z-books' 3D user interface. (a) A “traditional" published layout of image panels is depicted by pentagons. By and large, the current e-publishing paradigm simply mimics a traditional 2D reading experience: a user swipes through pages or scrolls through static, non-interactive elements. (b) A simple example of the same visual panels displayed by a Z-book-based e-publishing user interface is shown. Each panel is discretely divided as the same 2D image and imported into an infinite 3D environment. A virtual camera "flies" a user to each panel, allowing for a guided view in an immersive 3D world. (c) Our integrated menu system (depicted on a tablet viewer) allows for user-specified language settings to enable learning in many countries. Our multi-language translation functionality is cloud-based and can be updated remotely with new languages added on-the-fly. (d) Our custom "trigger-based" high-fidelity audio engine allows for interaction between complex narration, sound effects, and soundtracks. (e) Zbooks' proprietary 2D to 3D parallax interactivity creates interactive 3D elements from industry-standard 2D assets and places them into a limitless 3D environment with other 3D elements. These features make stories and learning come to life with a unique, interactive viewing experience. 
Immunology engagement and enjoyment data, obtaining a value of 0.00053 . This supported our hypothesis that the MR environment would significantly improve users' engagement while viewing presentations, which has been shown to increase overall learning outcomes related to ease of use, amount of effort exerted, and enjoyment. Similarly, for the Bioengineering article, MR presentation users had an average engagement score of $78.10 \%(\sigma=0.42)$, while PDF users had an average engagement score of $65.85 \%$ ( $\sigma=0.43 \mathrm{~A} t$ test was performed on the raw Bioengineering engagement and enjoyment data, obtaining a value of 0.000095 . Like the Immunology article results, this supported our hypothesis that the MR presentation would significantly improve users' learning outcomes. Overall, MR presentation users had $\sim 17 \%$ overall increases in a composite endpoint of engagement $(16.57 \%$ between Immunology groups and $18.60 \%$ between Bioengineering groups).

\section{$M R$ Presentation Improved ovErall Bioengineering Comprehension, Yet Failed to Improve Immunology Comprehension}

We then examined cognitive effectiveness, specifically comprehension between MR presentation and PDF users. This was measured based on average scores from multiple choice comprehension questions about content of the articles (see Appendix A). Comprehension trended toward significant improvement from using the MR presentation in a content-dependent manner (Fig. 4). For the Immunology article, comprehension was essentially identical between users who viewed the MR presentation versus PDFs, showing an average score of 0.70 across all 5 questions $(\sigma=0.24$ for MR presentation users and 0.21 for PDF users). A $t$ test was performed on the raw Immunology comprehension data, obtaining a value of 1.00 . This sug- gests that MR presentations do not always improve comprehension of the learning material. For the Bioengineering article, MR presentation users, who had an overall average score of $0.76(\sigma=0.21)$, exhibited significantly greater comprehension than PDF users, who had an overall average score of $0.58(\sigma=0.26)$. This revealed an increase in group average test score of +18 points ( $31 \%$ improvement) for the Bioengineering article presented through MR presentation versus PDFs. A $t$ test was performed on the raw Bioengineering comprehension data, obtaining a value of 0.056. Overall, more participants who viewed the MR presentation and not the PDFs for the Bioengineering article answered correctly for 4 of the 5 questions. The fifth question showed equal comprehension, so PDF users never outperformed MR presentation users.

\section{MR Presentation Increased Overall Time Spent Viewing Bioengineering Content, Yet Failed to Increase Overall Time Spent Viewing Immunology Content}

Finally, behavioral effectiveness was also studies by measuring time-on-task. Using a stopwatch, time spent viewing the material on the two presentation formats was recorded. As a group, there was a strong trend towards more time spent viewing content on the presentations $(p<0.20)$ in a content-dependent manner (Fig. 5). For the Immunology article, MR presentation users spent slightly less time viewing the presentation with an average of $246.5 \mathrm{~min}(\sigma=66.43)$ compared to PDF users with $252.1 \mathrm{~min}(\sigma=102.97)$. A t-test was performed on the raw Immunology time data, obtaining a value of 0.89 . These results suggest that MR presentation may detract from users' interests in the learning material. For the Bioengineering article, MR presentation users spent significantly more time viewing the presentation with an average of $220.7 \mathrm{~min}(\sigma=50.77)$ compared to PDF users with $189.9 \min (\sigma=67.81)$. On

\begin{tabular}{|ccc|}
\hline & Fold Improvement per Content Type (\%) \\
\hline Question & Immunology & Bioengineering \\
\hline This presentation software is easy to use. & 11.89 & 4.55 \\
\hline I enjoy using this presentation software. & 19.35 & 16.22 \\
\hline I felt engaged during this presentation. & 29.03 & 20.59 \\
\hline I find the presentation software to be aesthetically pleasing. & 51.72 & 33.33 \\
\hline I would like to read presentations in this format in the future. & 9.09 & 20.59 \\
\hline I was excited to learn what the next slide of the story would reveal. & 7.53 & 9.09 \\
\hline I found navigating through the presentation intuitive. & 5.41 & -2.70 \\
\hline I would be excited to create a presentation in this format. & 20.69 & 42.86 \\
\hline I am likely to recommend this presentation software to a friend or colleague. & 21.03 & 17.14 \\
\hline
\end{tabular}

FIGURE 2. Metrics of engagement increased. Nearly all questions of engagement, enjoyment, and recommendations of use were answered very positively when using Zyndo. 


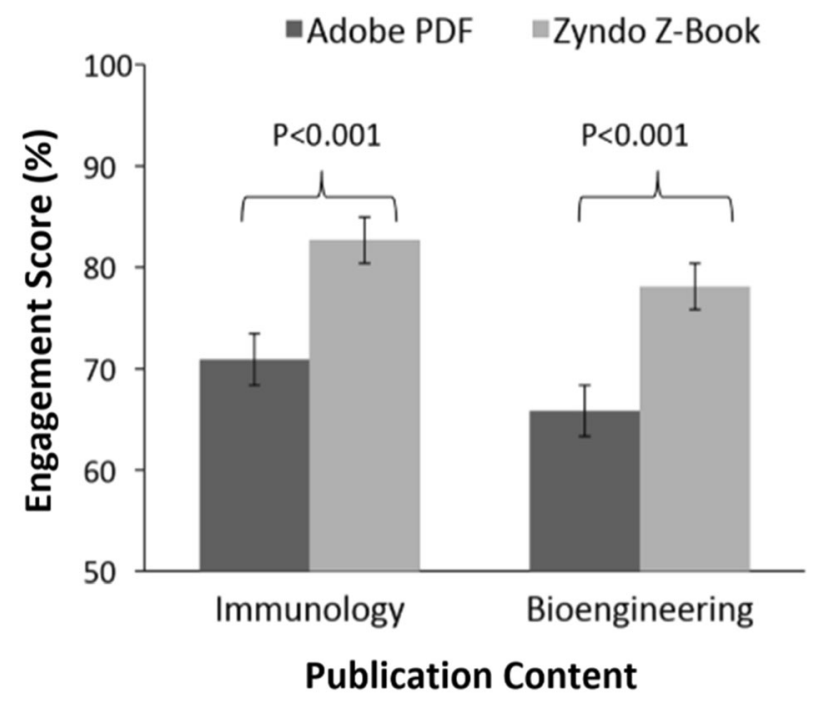

FIGURE 3. Mixed reality presentation significantly improved user engagement. Mixed reality presentation users had overall increases in a composite endpoint of engagement and enjoyment that was independent of content viewed $(12 \%$ or $13 \%$ total increase). This equates to $\sim 17 \%$ improvement in this measure.

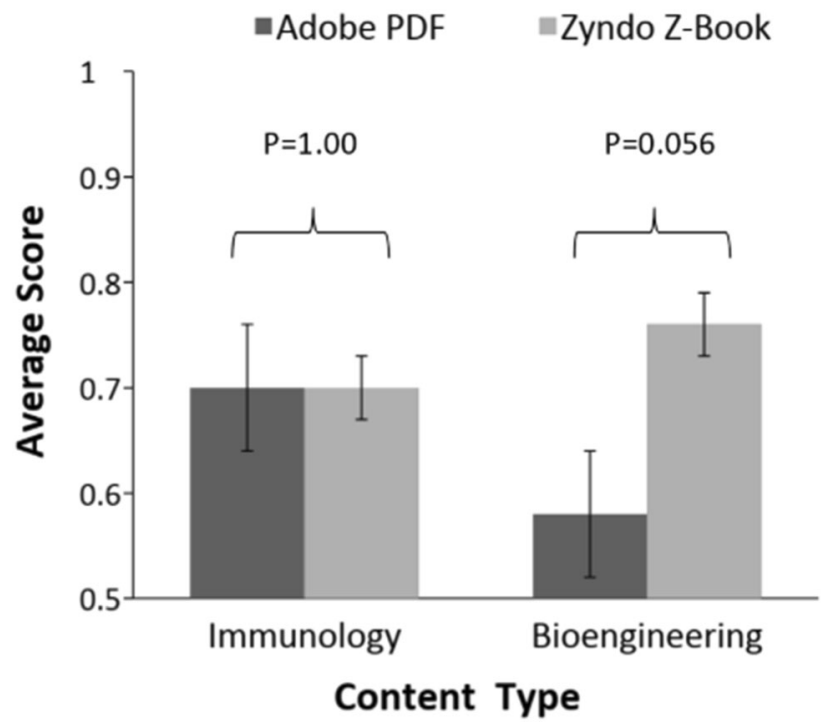

FIGURE 4. Mixed reality presentation sometimes improved comprehension. Comprehension trended toward significant improvement in a content-dependent manner. An increased group average test score (+18 points; $31 \%)$ was observed in Bioengineering content using the mixed reality presentation. Immunology content was comparable between the two presentation delivery platforms.

an individual level, about $66 \%$ of MR presentation users spent a greater amount of time with content. MR presentation users also spent a median of about $1 / 2$ minute more time with the content than PDF users (range 34 min). A t-test was performed on the raw Bioengineering time data, obtaining a value of 0.27 . In contrast to the Immunology article results, the time spent viewing the Bioengineering article increased from using the MR presentation than the PDFs, allowing users to better interact with and experience the content. We also examined whether age was related to the differences in times of use to account for age-dependent attention spans, but we found no correlation. These data suggest a potential mechanism for improved comprehension of Bioengineering content that is associated with increased time of viewing. Since this study was performed in a biomedical engineering research center, we speculate that the familiarity with bioengineering concepts helped with immersion into this specific article as a reflection of participant backgrounds.

\section{DISCUSSION}

Comprehension can be defined as how people construct meaning from reading and studying written and oral language. Measurements that study active comprehension include patterns of eye movement, reading time, and think aloud protocols. Comprehension is also evaluated using measurements after content is absorbed through recall tests, summaries of information, and answering questions. ${ }^{24}$ Adequate comprehension of scientific content lays the foundation for advanced STEM learning. A STEM-focused approach to teaching and learning was founded on the belief that students could comprehend and apply the multiple disciplines at once when asked to consider real-world problems. ${ }^{2,23,25}$ From a larger perspective, when students are presented with real world problems to solve, they must consider solutions that require problem solving and innovation to compete in the international career arena. Innovation is nurtured through STEM programs when they are committed to teaching and learning situations that welcome digital visual technologies that are developmentally appropriate for accurate, in-depth comprehension. ${ }^{12,19}$

Z-books have analytical tools that can potentially guide curriculum development. Robust analytics features are critical for better understanding students' responses to scientific content. The exact mechanisms and most helpful features that lead to the success of educational software are unclear. Most educational software is evaluated largely on correlations with test scores. Understanding the way in which users interact with the software may help determine which aspects are most important in retention and engagement. Publishing software analytics typically track only whether the user experience is positive, and not the actual interactions with features that directly lead to user happiness. Z-books contain analytic tools (Supplementary Table 1) that, in addition to user geography, device type, total views, and other analytic data, 

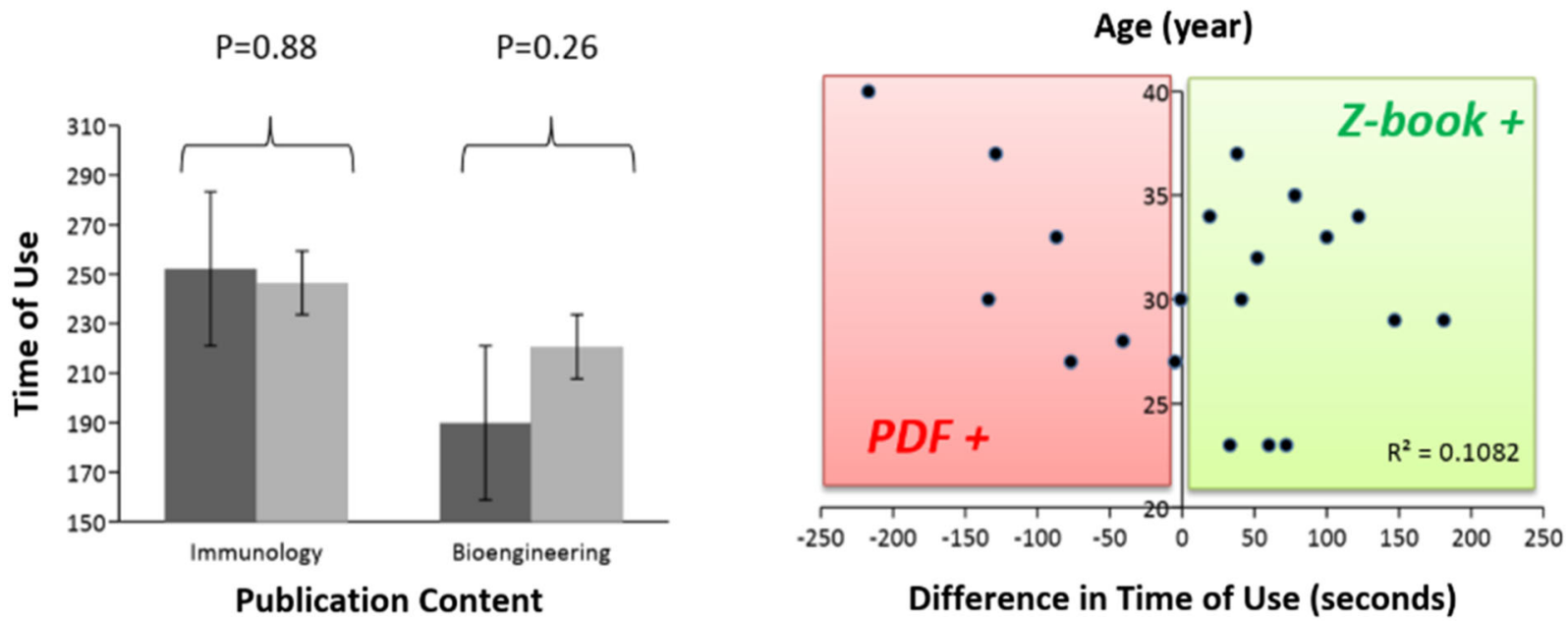

FIGURE 5. Users sometimes spent more time with the mixed reality presentation. As a group, there was a trend towards more time spent viewing Bioengineering content on the mixed reality presentation as a group, but not so in Immunology. This trend may be associated with improved comprehension of this group. No correlation was seen to age and may be impacted by limited sample size or a function of the specialized topic that was presented for this audience who had advanced education in scientific disciplines at the outset.

may also provide metrics aligned with optimizing STEM curricula. Among other things, instructors can see how much of each assignment is actually viewed, time spent within the app, and individual interactions within each section, object, problem, or 3D model. This unique information could potentially allow instructors to determine where students might be stuck, objects with which the most successful students interact, and numerous other data points around which curricula and lesson plans can be refined. New analytical tools, for instance, eye movement tracking that can more precisely quantify student observation, are under development for next generation Z-books.

Z-books have cross-platform capability that can help keep school district costs down and appeal to publishers for further academic incorporation and global distribution. Z-books can be used on computers, TVs, and mobile devices, allowing for cheaper incorporation and a much wider potential base of users. Already, half of all teen smartphone owners are "cell-mostly" internet users. This multi-platform capability also allows publishers to take advantage of the rapid growth of mobile devices to access STEM journals, which is occurring fastest among physicians and healthcare professionals. Furthermore, (though not studied herein) Z-books have integrated language translation that can also service the language gap in education and help smooth the incorporation of new non-native speakers into mixed-language classrooms by allowing instructors to create a single lesson for all students. This study explored this concept, albeit in a limited sample size $(N=20)$. Z-books are inherently scalable to greater sizes of classrooms and are limited by access to display devices, which may be challenging in resource-limited settings. Higher education students can be an initial demographic to focus on for advanced education and training methods based on these initial results. Our study used a journal article, which is typically narrow in focus, therefore evaluating a diversity of content will also be important moving forward. Results that are equated with comprehension of research article may not translate to other content such as entire introductory course in a subject and is worthy of further investigation by diversifying content materials. For younger demographics, larger studies with more quantitative endpoints and a diverse study body will be critical to perform to evaluate the benefits of Z-books on K-12 students who are developmentally different in regards to learning and brain function.

The results of this exploratory pilot study mainly focused on engagement and comprehension as indicative measures of overall learning outcomes for users of Z-books. Based on the results of this exploratory pilot study, which provided us with a baseline grasp of what metrics are important and how much improvement we should expect using MR platforms over PDFs, we propose using Z-books analytics in future studies while expanding the scale of study, diversifying the learning content and student population, and adding more short- and long-term quantifiable metrics to learning outcomes. Z-books unique back-end analytics platform can extend the scope of our metrics beyond levels of engagement, comprehension, and time of use. Further research involving Z-book's analytics will not only 
improve STEM education for people of all ages, but also enhance the capabilities of the Z-book platform by providing more data on which analytical tools are crucial for allowing teachers to effectively gauge student learning.

\section{APPENDIX A: BACKGROUND INFORMATION}

Age (Optional)?

Degree Type?

On what device(s) do you typically view presentations? Please list all.

Which software do you typically use to view presentations?

Which, if any, program do you typically use to create presentation? Please list all.

1. What is the purpose of the drug delivery device?

a. To release a great deal of the drug all at once

b. To release a steady and continuous amount of the drug

c. To release the drug periodically over a long period of time

d. To release the drug as needed
2. What is P1NP a marker for?
a. Bone loss
b. Bone fracture
c. Bone formation
d. Bone inflammation

3. What are the respective sizes of a single microchip, a single device, and a single reservoir?
a. $\quad 27 \mathrm{~mm} \times 15 \mathrm{~mm} ; 54 \mathrm{~mm} \times 31 \mathrm{~mm} ; 6 \mathrm{~nL}$
b. $\quad 13 \mathrm{~mm} \times 5.4 \mathrm{~mm} ; 54 \mathrm{~mm} \times 31 \mathrm{~mm} ; 600 \mathrm{~nL}$
c. $\quad 2.7 \mathrm{~mm} \times 1.5 \mathrm{~mm} ; 54 \mathrm{~mm} \times 15 \mathrm{~mm} ; 60 \mathrm{~nL}$
d. $\quad 27 \mathrm{~mm} \times 15 \mathrm{~mm} ; 54 \mathrm{~mm} \times 15 \mathrm{~mm} ; 60 \mathrm{~nL}$

4. How does the amount of drug released from an activated microchip compare to a typical single injection?
a. Same
b. Larger
c. Smaller
d. It varies

5. What kind of drug is being tested in this study?
a. Antibiotic
b. Growth Factor
c. Anti-inflammatory
d. Anti-osteoporosis 
6. This presentation software is easy to use.

\begin{tabular}{|c|c|c|c|c|}
\hline $\begin{array}{c}\text { Strongly } \\
\text { Disagree } \\
\mathbf{1}\end{array}$ & $\mathbf{2}$ & $\mathbf{3}$ & $\mathbf{4}$ & $\begin{array}{c}\text { Strongly } \\
\text { Agree } \\
\mathbf{5}\end{array}$ \\
\hline 0 & 0 & 0 & 0 & 0 \\
\hline
\end{tabular}

7. I enjoy using this presentation software.

\begin{tabular}{|c|c|c|c|c|}
\hline $\begin{array}{c}\text { Strongly } \\
\text { Disagree } \\
\mathbf{1}\end{array}$ & $\mathbf{2}$ & $\mathbf{3}$ & $\mathbf{4}$ & $\begin{array}{c}\text { Strongly } \\
\text { Agree } \\
\mathbf{5}\end{array}$ \\
\hline 0 & 0 & 0 & 0 & 0 \\
\hline
\end{tabular}

8. I felt engaged during this presentation.

\begin{tabular}{|c|c|c|c|c|}
\hline $\begin{array}{c}\text { Strongly } \\
\text { Disagree } \\
\mathbf{1}\end{array}$ & $\mathbf{2}$ & $\mathbf{3}$ & $\mathbf{4}$ & $\begin{array}{c}\text { Strongly } \\
\text { Agree } \\
\mathbf{5}\end{array}$ \\
\hline 0 & 0 & 0 & 0 & 0 \\
\hline
\end{tabular}

9. I find the presentation software to be aesthetically pleasing.

\begin{tabular}{|c|c|c|c|c|}
\hline $\begin{array}{c}\text { Strongly } \\
\text { Disagree } \\
\mathbf{1}\end{array}$ & $\mathbf{2}$ & $\mathbf{3}$ & $\mathbf{4}$ & $\begin{array}{c}\text { Strongly } \\
\text { Agree } \\
\mathbf{5}\end{array}$ \\
\hline 0 & 0 & 0 & 0 & 0 \\
\hline
\end{tabular}

10. I would like to read presentations in this format in the future.

\begin{tabular}{|c|c|c|c|c|}
\hline $\begin{array}{c}\text { Strongly } \\
\text { Disagree } \\
\mathbf{1}\end{array}$ & $\mathbf{2}$ & $\mathbf{3}$ & $\mathbf{4}$ & $\begin{array}{c}\text { Strongly } \\
\text { Agree } \\
\mathbf{5}\end{array}$ \\
\hline 0 & 0 & 0 & 0 & 0 \\
\hline
\end{tabular}

11. I was excited to learn what the next slide of the story would reveal.

\begin{tabular}{|c|c|c|c|c|}
\hline $\begin{array}{c}\text { Strongly } \\
\text { Disagree } \\
\mathbf{1}\end{array}$ & $\mathbf{2}$ & $\mathbf{3}$ & $\mathbf{4}$ & $\begin{array}{c}\text { Strongly } \\
\text { Agree } \\
\mathbf{5}\end{array}$ \\
\hline 0 & 0 & 0 & 0 & 0 \\
\hline
\end{tabular}


12. I felt engaged during this presentation.

\begin{tabular}{|c|c|c|c|c|}
\hline $\begin{array}{c}\text { Strongly } \\
\text { Disagree } \\
\mathbf{1}\end{array}$ & $\mathbf{2}$ & $\mathbf{3}$ & $\mathbf{4}$ & $\begin{array}{c}\text { Strongly } \\
\text { Agree } \\
\mathbf{5}\end{array}$ \\
\hline 0 & 0 & 0 & 0 & 0 \\
\hline
\end{tabular}

13. I found navigating through the presentation intuitive.

\begin{tabular}{|c|c|c|c|c|}
\hline $\begin{array}{c}\text { Strongly } \\
\text { Disagree } \\
\mathbf{1}\end{array}$ & $\mathbf{2}$ & $\mathbf{3}$ & $\mathbf{4}$ & $\begin{array}{c}\text { Strongly } \\
\text { Agree } \\
\mathbf{5}\end{array}$ \\
\hline 0 & 0 & 0 & 0 & 0 \\
\hline
\end{tabular}

14. I would be excited to create a presentation in this format.

\begin{tabular}{|c|c|c|c|c|}
\hline $\begin{array}{c}\text { Strongly } \\
\text { Disagree } \\
\mathbf{1}\end{array}$ & $\mathbf{2}$ & $\mathbf{3}$ & $\mathbf{4}$ & $\begin{array}{c}\text { Strongly } \\
\text { Agree } \\
\mathbf{5}\end{array}$ \\
\hline 0 & 0 & 0 & 0 & 0 \\
\hline
\end{tabular}

15. I am likely to recommend this presentation software to a friend or colleague.

\begin{tabular}{|c|c|c|c|c|}
\hline $\begin{array}{c}\text { Strongly } \\
\text { Disagree } \\
\mathbf{1}\end{array}$ & $\mathbf{2}$ & $\mathbf{3}$ & $\mathbf{4}$ & $\begin{array}{c}\text { Strongly } \\
\text { Agree } \\
\mathbf{5}\end{array}$ \\
\hline 0 & 0 & 0 & 0 & 0 \\
\hline
\end{tabular}

1. What was the major finding of the study?
a. A link between anti-cancer therapy and the gut microbiome
b. A link between antibiotics and anti-cancer therapy
c. A link between antibiotics and the skin microbiome
d. A link between anti-cancer therapy and the skin microbiome

2. How did the antibody drug impact the microbiome?
a. Indirectly, through increased beneficial microbial cells
b. Directly, through increased beneficial microbial cells
c. Directly, through reducing unwanted microbial cells
d. Indirectly, through intestinal barrier breach

3. What is the effect of combining the antibody drug with specific microbiome cells?
a. Infection was significantly reduced
b. Cancer was significantly reduced
c. Infection was significantly increased
d. Cancer was significantly increased

4. What type of immune response occurred after antibody treatment in both mice and humans?
a. Natural Killer Cell response
b. Memory T Cell response
c. Regulatory B Cell response
d. Granulomatous Cell response

5. Which mice responded to antibody drug?
a. Obese
b. Immunocompromised
c. Normal
d. Germ-free 
6. This presentation software is easy to use.

\begin{tabular}{|c|c|c|c|c|}
\hline $\begin{array}{c}\text { Strongly } \\
\text { Disagree } \\
\mathbf{1}\end{array}$ & $\mathbf{2}$ & $\mathbf{3}$ & $\mathbf{4}$ & $\begin{array}{c}\text { Strongly } \\
\text { Agree } \\
\mathbf{5}\end{array}$ \\
\hline 0 & 0 & 0 & 0 & 0 \\
\hline
\end{tabular}

7. I enjoy using this presentation software.

\begin{tabular}{|c|c|c|c|c|}
\hline $\begin{array}{c}\text { Strongly } \\
\text { Disagree } \\
\mathbf{1}\end{array}$ & $\mathbf{2}$ & $\mathbf{3}$ & $\mathbf{4}$ & $\begin{array}{c}\text { Strongly } \\
\text { Agree } \\
\mathbf{5}\end{array}$ \\
\hline & 0 & 0 & 0 & 0 \\
\hline
\end{tabular}

8. I felt engaged during this presentation.

\begin{tabular}{|c|c|c|c|c|}
\hline $\begin{array}{c}\text { Strongly } \\
\text { Disagree } \\
\mathbf{1}\end{array}$ & $\mathbf{2}$ & $\mathbf{3}$ & $\mathbf{4}$ & $\begin{array}{c}\text { Strongly } \\
\text { Agree } \\
\mathbf{5}\end{array}$ \\
\hline & 0 & 0 & 0 & 0 \\
\hline
\end{tabular}

9. I find the presentation software to be aesthetically pleasing.

\begin{tabular}{|c|c|c|c|c|}
\hline $\begin{array}{c}\text { Strongly } \\
\text { Disagree } \\
\mathbf{1}\end{array}$ & $\mathbf{2}$ & $\mathbf{3}$ & $\mathbf{4}$ & $\begin{array}{c}\text { Strongly } \\
\text { Agree } \\
\mathbf{5}\end{array}$ \\
\hline 0 & 0 & 0 & 0 & 0 \\
\hline
\end{tabular}

10. I would like to read presentations in this format in the future.

\begin{tabular}{|c|c|c|c|c|}
\hline $\begin{array}{c}\text { Strongly } \\
\text { Disagree } \\
\mathbf{1}\end{array}$ & $\mathbf{2}$ & $\mathbf{3}$ & $\mathbf{4}$ & $\begin{array}{c}\text { Strongly } \\
\text { Agree } \\
\mathbf{5}\end{array}$ \\
\hline 0 & 0 & 0 & 0 & 0 \\
\hline
\end{tabular}

11. I was excited to learn what the next slide of the story would reveal.

\begin{tabular}{|c|c|c|c|c|}
\hline $\begin{array}{c}\text { Strongly } \\
\text { Disagree } \\
\mathbf{1}\end{array}$ & $\mathbf{2}$ & $\mathbf{3}$ & $\mathbf{4}$ & $\begin{array}{c}\text { Strongly } \\
\text { Agree } \\
\mathbf{5}\end{array}$ \\
\hline & 0 & 0 & 0 & 0 \\
\hline
\end{tabular}


12. I felt engaged during this presentation.

\begin{tabular}{|c|c|c|c|c|}
\hline $\begin{array}{c}\text { Strongly } \\
\text { Disagree } \\
\mathbf{1}\end{array}$ & $\mathbf{2}$ & $\mathbf{3}$ & $\mathbf{4}$ & $\begin{array}{c}\text { Strongly } \\
\text { Agree } \\
\mathbf{5}\end{array}$ \\
\hline 0 & 0 & 0 & 0 & 0 \\
\hline
\end{tabular}

13. I found navigating through the presentation intuitive.

\begin{tabular}{|c|c|c|c|c|}
\hline $\begin{array}{c}\text { Strongly } \\
\text { Disagree } \\
\mathbf{1}\end{array}$ & $\mathbf{2}$ & $\mathbf{3}$ & $\mathbf{4}$ & $\begin{array}{c}\text { Strongly } \\
\text { agree } \\
\mathbf{5}\end{array}$ \\
\hline 0 & 0 & 0 & 0 & 0 \\
\hline
\end{tabular}

14. I would be excited to create a presentation in this format.

\begin{tabular}{|c|c|c|c|c|}
\hline $\begin{array}{c}\text { Strongly } \\
\text { Disagree } \\
\mathbf{1}\end{array}$ & $\mathbf{2}$ & $\mathbf{3}$ & $\mathbf{4}$ & $\begin{array}{c}\text { Strongly } \\
\text { Agree } \\
\mathbf{5}\end{array}$ \\
\hline 0 & 0 & 0 & 0 & 0 \\
\hline
\end{tabular}

15. I am likely to recommend this presentation software to a friend or colleague.

\begin{tabular}{|c|c|c|c|c|}
\hline $\begin{array}{c}\text { Strongly } \\
\text { Disagree } \\
\mathbf{1}\end{array}$ & $\mathbf{2}$ & $\mathbf{3}$ & $\mathbf{4}$ & $\begin{array}{c}\text { Strongly } \\
\text { Agree } \\
\mathbf{5}\end{array}$ \\
\hline 0 & 0 & 0 & 0 & 0 \\
\hline
\end{tabular}

\section{SUPPLEMENTARY INFORMATION}

The online version contains supplementary material available at https://doi.org/10.1007/s43683-021-00049w.

\section{ACKNOWLEDGMENTS}

We greatly appreciate all study participants for their contribution and feedback regarding this study.

\section{AUTHOR CONTRIBUTIONS}

PG, JS, DS, BP conceived of study design. PG coordinated study by consenting, enrolling, and administering study procedures. PG, JS, DD, DS and BP drafted manuscript. All authors reviewed and approved the final manuscript. BP developed didactic presentation and comprehension evaluation questions. JW, ZL produced final audiovisual content from a common presentation file and provided funding for the study.

\section{FUNDING}

This research was supported by in-kind support by Zyndo, LLC.

\section{DATA AVAILABILITY}

Study materials and availability of data can be freely made available upon request. 


\section{CONFLICT OF INTEREST}

ZL, JW are equity shareholders of Zyndo, LLC. The remaining authors have no conflicts of interest.

\section{ETHICAL APPROVAL}

An institutional review board within Zyndo LLC approved the consent and study design for human subjects research.

\section{INFORMED CONSENT}

All study participants were enrolled into the study through a consent process that was communicated through study coordinators.

\section{OPEN ACCESS}

This article is licensed under a Creative Commons Attribution 4.0 International License, which permits use, sharing, adaptation, distribution and reproduction in any medium or format, as long as you give appropriate credit to the original author(s) and the source, provide a link to the Creative Commons licence, and indicate if changes were made. The images or other third party material in this article are included in the article's Creative Commons licence, unless indicated otherwise in a credit line to the material. If material is not included in the article's Creative Commons licence and your intended use is not permitted by statutory regulation or exceeds the permitted use, you will need to obtain permission directly from the copyright holder. To view a copy of this licence, visit http://crea tivecommons.org/licenses/by/4.0/.

\section{REFERENCES}

${ }^{1}$ Atwood-Blaine D, Huffman D. Mobile Gaming and student interactions in a science center: the future of gaming in science education. Int J Sci Math Educ. 2017;15:45-65.

${ }^{2}$ Beane DB. Say yes to a youngster's future: a model for home, school, and community partnership. J Negro Educ. 1990;59(3):360-74.

${ }^{3}$ Boykin AW, Noguera P. Creating the opportunity to learn: Moving from research to practice to close the achievement gap. Alexandria: Ascd; 2011.

${ }^{4} \mathrm{Cai} \mathrm{S}$, et al. Applications of augmented reality-based natural interactive learning in magnetic field instruction. Interact Learn Environ. 2017;25(6):778-91.

${ }^{5}$ Chapman E. Alternative approaches to assessing student engagement rates. Pract Assess Res Eval. 2003;8(13):1-10.

${ }^{6}$ Chen C-H, Huang C-Y, Chou Y-Y, Effects of augmented reality-based multidimensional concept maps on students' learning achievement, motivation and acceptance; 2017. p. $1-12$.

${ }^{7}$ Christenson SL, Reschly AL, Wylie C. Handbook of Research on Student Engagement. NewYork: Springer; 2012.
${ }^{8}$ Ciborowski J. Textbooks and the students who can't read them: a guide to teaching content. The cognitive strategy training series. Washington: ERIC; 1992.

${ }^{9}$ Connell JP, Wellborn JG. Competence, autonomy, and relatedness: A motivational analysis of self-system processes. New York: University of Rochester; 1991.

${ }^{10}$ Duckworth E. The having of wonderful ideas and other essays on teaching and learning. New York: Teachers College Press; 2006.

${ }^{11}$ Farra R, et al. First-in-human testing of a wirelessly controlled drug delivery microchip. Sci Transl Med. 2012;4(122):3003276.

${ }^{12}$ Flood A, Bamford A. Manipulation, simulation, stimulation: the role of art education in the digital age. Int $\mathbf{J}$ Educ Art. 2007;3(2):91-102.

${ }^{13}$ Fredricks $\mathbf{J}$ et al. Measuring Student Engagement in Upper Elementary through High School: A Description of 21 Instruments. Issues \& Answers. REL 2011-No. 098. Regional Educational Laboratory Southeast; 2011.

${ }^{14}$ Garner R, et al. Interest and learning from text. Am Educ Res J. 1991;28(3):643-59.

${ }^{15}$ Glynn SM, Yeany RH, Britton BK. A constructive view of learning science. In: Glynn SM, Yeany RH, Britton BK, editors. The Psychology of Learning Science. Hillsdale: Lawrence Erlbaum Associates; 1991. p. 3-19.

${ }^{16}$ Guo W et al. Utilizing Augmented Reality to Support Students' Learning in Popular Science Courses. In: 2017 International Conference of Educational Innovation through Technology (EITT). IEEE.

${ }^{17} \mathrm{Hsu}$ Y-S, et al. Impact of augmented reality lessons on students' STEM interest. Res Pract Technol Enhanced Learn. 2017;12(1):2.

${ }^{18}$ Isseks MJEL. How PowerPoint is killing education. Educ Leadersh. 2011;68(5):74-6.

${ }^{19}$ Ito $\mathrm{H}$, et al. Learning science where cognitive neuroscience meets psychotherapy. Psychologia. 2008;51(4):280-9.

${ }^{20}$ Lindgren R, et al. Enhancing learning and engagement through embodied interaction within a mixed reality simulation. Comput Educ. 2016;95:174-87.

${ }^{21}$ Liou $\mathrm{H}-\mathrm{H}$, et al. The influences of the $2 \mathrm{~d}$ image-based augmented reality and virtual reality on student learning. $\mathbf{J}$ Educ Technol Soc. 2017;20(3):110-21.

${ }^{22}$ Luna Scott C. The Futures of Learning 3: What kind of pedagogies for the 21st century? Paris: UNESCO; 2015.

${ }^{23}$ Mentzer GA, Czerniak CM, Duckett TR. Comparison of two alternative approaches to quality STEM teacher preparation: fast-track licensure and embedded residency programs. School Sci Math. 2019;119(1):35-48.

${ }^{24}$ Otero J, Graesser AC. The psychology of science text comprehension. London: Routledge; 2014.

${ }^{25}$ Pleasants J, et al. Fundamental issues regarding the Nature of Technology. Sci Educ. 2019;28(3):561-97.

${ }^{26}$ Reading, C. Recognising and measuring engagement in ICT-rich learning environments. In: Australian Computers in Education Conference; 2008.

${ }^{27}$ Safadel P, White D. A comparative analysis of augmented reality and two-dimensional using molecular modeling on student learning. In: Society for Information Technology \& Teacher Education International Conference. Association for the Advancement of Computing in Education (AACE); 2017.

${ }^{28}$ Shernoff DJ. Optimal learning environments to promote student engagement. New York: Springer; 2013. 
${ }^{29}$ System Usability Scale (SUS). https://www.usability.gov/h ow-to-and-tools/methods/system-usability-scale.html (2018). Accessed 27 Oct 2018.

${ }^{30}$ Tanenbaum, C. STEM 2026: A vision for innovation in STEM education. Washington, D.C.; 2016.

${ }^{31}$ Vétizou M, et al. Anticancer immunotherapy by CTLA-4 blockade relies on the gut microbiota. Science. 2015;350(6264):1079-84.
${ }^{32}$ Xingeng D, Jianxiang L, Engineering M. Advantages and disadvantages of PowerPoint in lectures to science students. IJ Educ Manag Eng. 2012;9:61-5.

Publisher's Note Springer Nature remains neutral with regard to jurisdictional claims in published maps and institutional affiliations. 